\title{
Relationships Between AAA and Cauda Equina Syndrome
}

\author{
Masood Rehman Moghul and Bassel El-Osta \\ North-West London Hospitals NHS Trust, \\ UK
}

\section{Introduction}

Lower back pain is one of the most common clinical presentations in general practice, with a lifetime prevalence of around $70-80 \%$ [1,2]. A small proportion of these patients will be recommended for immediate further investigation, those that demonstrate: loss of sphincter control, progressive lower limb motor weakness, saddle anaesthesia or signs of bilateral nerve root involvement; all symptoms and signs of the surgical emergency Cauda Equina syndrome (CES) [3].

\section{Vertebral column}

The vertebral column consists of 33 [4] individual vertebrae: 7 cervical, 12 thoracic, 5 lumbar, 5 sacral and 4 (this can vary between 3 and 5 [5]) coccygeal bony vertebrae [4,5]; protecting the spinal cord (and nerves) that traverse between them $[4,6]$. The sacral and coccygeal vertebrae are normally fused in adults leaving 24 articulating vertebrae $[4,5]$. This is demonstrated in figure 1 .

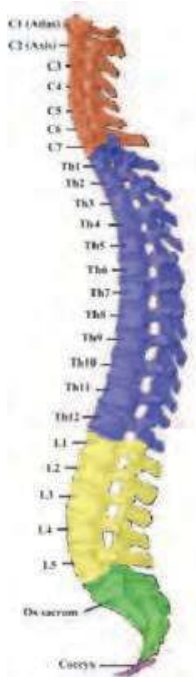

Fig. 1. Showing the vertebral column. 


\subsection{Vertebrae}

The vertebrae are bound together via several ligaments and between each vertebrae, resting on the body of each, lie the strong intervertebral discs. Anteriorly and posteriorly are the anterior longitudinal and posterior longitudinal ligaments respectively $[4,5,7]$. In addition the posterior aspects of the vertebrae are attached to one other by the supraspinous and intraspinous ligaments, posterior facet joints and the ligamentum flavum. [5,7]. Figure 2 illustrates these.

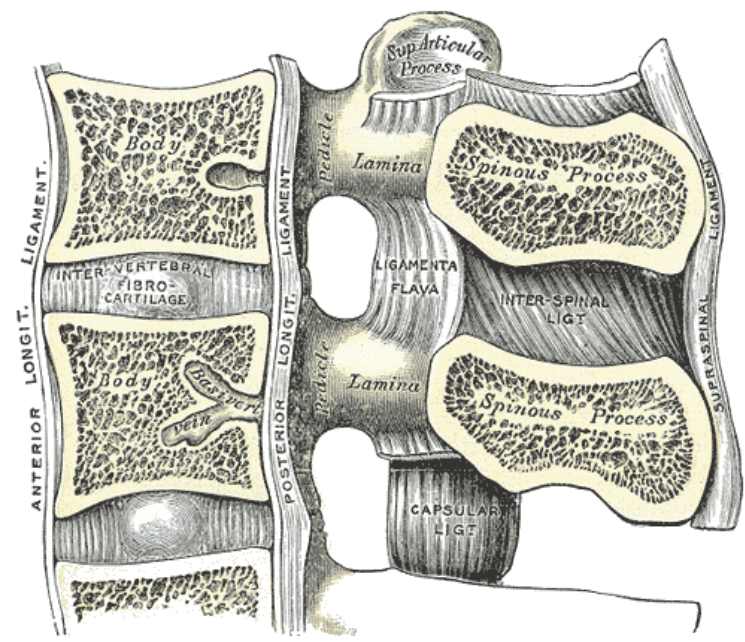

Fig. 2. Showing the ligaments of the vertebral column.

\subsection{Spinal cord}

The spinal cord is the extension of the medulla oblongata of the brainstem [4,6]. Measuring between $42 \mathrm{~cm}$ and $45 \mathrm{~cm}$ (from the foramen magnum to L2) it is the structure responsible for relaying information to the brain, and passing commands down $[4,6,8]$. It passes through the vertebral canal, which is made by the vertebral foraminae of consecutive vertebrae using the body, pedicles and vertebral arch [4], as well as the iv discs [5]. The canal continues in the fused sacrum through the sacral canal [5]. It has two enlargements due to innervations for upper and lower limbs, cervical and lumbar (upper and lower limbs respectively) $[4,6]$. Caudal to the lumbar enlargement the cord suddenly narrows to form a cone shaped termination: conus medullaris [6] at L1-L2 (although this may be as high as T12 or as low L3 [4]). Hence the spinal cord only occupies the superior two-thirds of the vertebral canal [4]. This is due to a slower growth rate of the cord compared with the vertebral column $[4,6]$.

The cord itself is a cylindrical structure [6]. It is split into an ' $\mathrm{H}$ ' shaped darker grey matter surrounded by the peripheral white matter [6,8]. The four projections of the grey matter (two dorsal and two ventral horns) are sites of attachment for peripheral nerves [6]. The dorsal horn contains sensory afferent fibres whilst the ventral horn contains efferent motor (skeletal muscle) fibres [6]. A lateral horn is also present at thoracic and upper lumbar levels, containing autonomic neurones [6]. The white matter is organised into a series of longitudinally running ascending and descending neuronal tracts [6]. This is demonstrated in figure 3. 


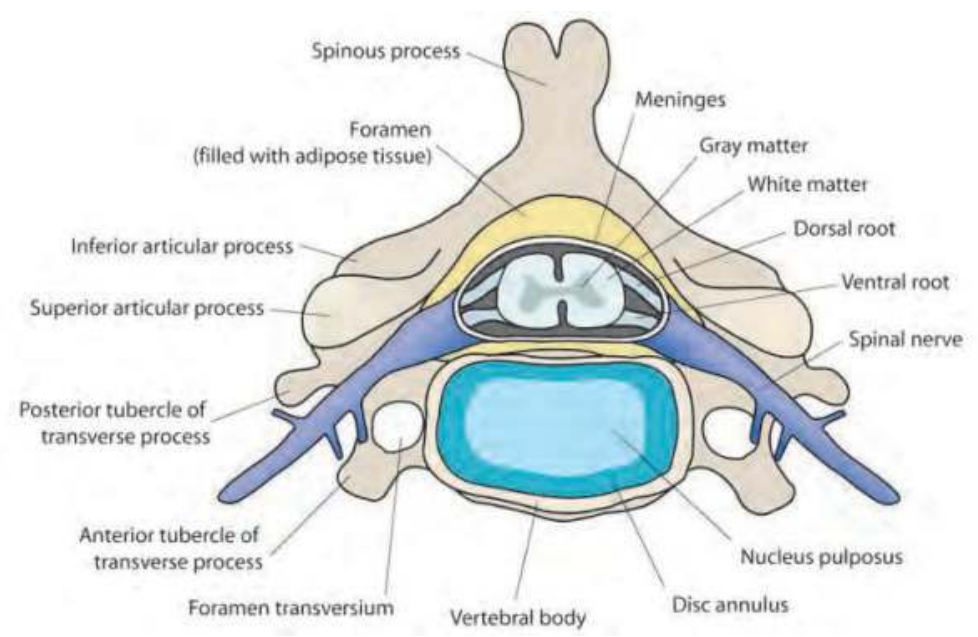

Fig. 3. Showing a cross-sectional view of a typical cervical vertebrae with the spinal cord.

\subsection{Spinal nerves}

The spinal cord connects to the periphery via 31 pairs of spinal nerves: 8 cervical, 12 thoracic, 5 lumbar, 5 sacral and a solitary coccygeal nerve [4,6]. Each nerve is formed by the uniting of ventral and dorsal nerve roots close to the cord $[4,5]$. The mixed spinal nerves pass within the intervertebral foraminae (formed by the joining of subsequent superior and inferior vertebral notches ${ }^{[4]}$ ) and immediately divide into dorsal and ventral rami $[4,5,6]$. The dorsal ramus (thinner and posterior) supplies the true muscles and skin of the back region $[4,6]$. The ventral (larger and anterior) ramus supplies skin and muscles of front of body and limbs $[4,6]$, giving rise to the myotome and dermatome distribution patterns [6].

Due to the differing lengths of the cord and canal, below the cervical region successive spinal nerve roots follow a progressively longer course to reach their respective intervertebral foraminae, through which they must exit. This is most notable in the Cauda Equina [6]. The Cauda Equina contains the dorsal and ventral nerve roots of lumbar, sacral and coccygeal nerves $[4,6]$. Each level of the spinal cord is numbered according to the IV foraminae through which the dorsal and ventral roots exit the vertebral canal $[4,8]$.

\subsection{Meninges}

As with the brain the spinal cord has 3 meningeal coverings. The innermost is the pia mater; a thin, delicate, vascular membrane, covering the cord, nerve roots and cauda equina [4,6]. The arachnoid mater is a loose-fitting layer separated from the pia mater by the subarachnoid space containing cerebrospinal fluid [6]. The outermost covering, the dura mater, is tougher, fibrous sheath, continuous with its cranial counterpart $[4,6]$. The dura is kept away from the walls of the vertebral canal by adipose tissue and internal vertebral venous plexuses [4,6]. Even though the spinal cord terminates at L1-L2 the arachnoid and dural sheaths continue to S2, even forming meningeal sleeves that cover the nerve roots, which later become continuous with the epineurium sheathing the spinal nerve ${ }^{[4,6]}$. The filum terminale is a remnant of the embryological spinal cord made out of connective tissue $[4,6]$. It exits the dural sac at S2 and attaches to the coccyx, securing the cord $[4,6]$. 


\subsection{Vasculature of the vertebral column}

Most vertebrae are supplied by segmental vessels and spinal arteries, which distribute to the vertebrae, are branches of the (descending order): cervical, posterior intercostal, subcostal, lumbar, iliolumbar and sacral arteries [4]. These spinal arteries enter the IV foraminae and divide into terminal radicular arteries, which supply dorsal and ventral roots and their coverings (and also some of the superficial grey matter), although some radicular arteries continue as medullary segmental arteries that anastamose with spinal arteries [4].

As previously mentioned internal venous plexuses lie within the vertebral canal, and external plexuses lie outside [4]. They receive blood from large tortuous basivertebral veins lying within vertebral and IV veins (both passing through the IV foraminae), which receives veins from the spinal cord and vertebral plexuses ${ }^{[4]}$.

\subsection{Spinal cord vasculature}

Arterial supply to the spinal cord is through three main longitudinal spinal arteries: one anterior and two posteriors $[4,6]$. The anterior spinal artery, formed by the joining of the vertebral arteries (at the level of the medulla), runs in the anteromedian fissure of the cord itself [4,6,9-12]. Sulcul (central) arteries from it enter the cord through the fissure [9], supplying two-thirds of the cross-sectional area of the spinal cord $[4,10,11]$. Blood flow through the anterior spinal artery is predominantly caudal (away from the head) [9]. The posterior arteries are branches of either the vertebral artery or posterior-inferior cerebellar arteries $[4,6,11]$, with blood flow towards the head (rostral) [9]. They supply the posterior one thirds of the cord and receive collaterals from around 12 unpaired radicular arteries, whilst the anterior cerebral arteries have a less effective collateral circulation with 6-10 unpaired radicular brances [11,12].

The anterior longitudinal artery only supplies the superior cord, with the remainder being supplied by the segmental medullary and radicular arteries previously mentioned $(4,6)$. These run along spinal nerve roots and in the case of segmental medullary arteries are located where the need for blood is greatest: at the cervical and lumbosacral cord enlargements $(4,6)$. Deficiencies in the number of segmental arteries increase susceptibility to ischemia [10].

The great anterior segmental medullary artery of Adamkiewicz (GRA) forms from the inferior intercostal or upper lumbar arteries and enters the vertebral canal via one of their IV foraminae $[4,6,9]$. It arises around T9-L2 and is larger than other segmental arteries and has significance as it reinforces circulation to the inferior cord including the lumbosacral enlargements $[4,11,12)]$.

Spinal veins follow similar paths as arteries but with 3 anterior and 3 posterior spinal veins $[4,6]$. They communicate with each other freely and are drained by up to 12 anterior and posterior radicular and medullary veins $[4,6]$. They also join internal venous plexuses in the extradural space, which communicate with the external plexuses and then the ascending lumbar, azygous and hemiazygous veins $[4,6]$.

\section{Spinal injury - Cauda equina}

There are various types of spinal injury, however most remain out of the scope of this chapter. This chapter focuses particularly on two types: Cauda Equina syndrome and spinal cord ischaemia, also known as spinal stroke and in particular how they may share characteristics. Cord damage and compression can cause similar symptoms in any area of the cord however; CES is a particular syndrome when this happens in the inferior cord. 
Cauda Equina syndrome is caused by injury to the lumbosacral nerve roots, contained within the Cauda Equina (figure 4) grossly causing pain, bladder and bowel disturbances as well as focal neurology in the lower limb [4,8]. Essentially any mechanism which can cause compression of the spinal nerve roots, thereby causing shear stresses as well as obstructing blood flow in the vasculature of the nerve roots can cause CES [13]. The most common is cause herniation of the nucleus pulposus, $2 \%$ of which cause CES [14,15]. This is especially common in the lumbar spine where the lumbosacral enlargement means the spinal nerves are increasing in size caudally, but the IV foraminae size decrease [4]. The $5^{\text {th }}$ lumbar disc is the most common "slipped disc" causing trauma to the roots of the first sacral nerve [6].

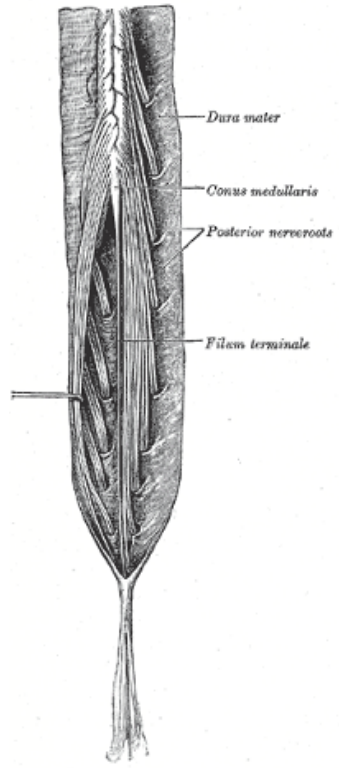

Fig. 4. Showing the cauda equina.

Other causes are: spinal cord stenosis, blunt or direct injury through the cauda equina, sacral fractures [16], hematomas, abscesses, lymphomas, solid tumors and other spaceoccupying lesions [11,14,15]. Rare causes include: ankylosing spondylitis, inferior vena cava thrombosis, sarcoid, and demyelinating lesions [14,15]. CES can occur as a complication of spinal anaesthesia but is rather rare [17]. The cauda equina is supplied by blood from the sacral arteries, which arise from the hypogastric artery [11].

Symptoms can vary depending on the size and location of the lesion. Above the vertebrae L1 (conus medullaris) damage can affect the cord itself or the roots, or both simultaneously however, below this level only the roots can be damaged [11]. Root damage causes lower motor neurone effects and sensory impairment in the affected root only, whilst segmental damage to the cord causes similar effects in the same segmental level but will also cause upper motor neurone effects and a sensory deficit below the level of the lesion [11]. This is due to interruption of the cord fibres. Root damage causes severe sharp, shooting, even burning pain radiating in the specific myotome and dermatome distribution of the root, exacerbated with movement [11]. Segmental damage causes continuous deep, aching pain, 
which radiates into either one lower limb or one half of the body, and that is not affected by movement [11]. Hence upper cauda equina may cause root or segmental effects with late bladder involvement, whilst a lower cauda equina lesion causes root damage, with early bladder incontinence and saddle anaesthesia (S2-S5) [11].

History and examination can frequently yield key clues to the diagnosis. Spinal imaging is usually required to confirm diagnoses with MRI being the gold standard, CT scanning can illustrate protrusions, X-rays are of little benefit but can show loss of disc space or collapse [11].

\section{Spinal cord infarction ("spinal stroke")}

Spinal cord infarction is a stroke that occurs within the spinal cord or the arteries that supply it, usually caused by atherosclerosis of the major arteries to the spinal cord [18-20]. It is rare compared to cerebral stroke [10,14,21], accounting for approximately $1-2 \%$ of all strokes $[22,23]$. Spinal stroke can be categorised into two types: local interference with the blood supply (trauma, embolism, aortic surgery, aortic dissection etc.), and generalised hypoxia/hypoperfusion (e.g. cardiac arrest) where often the brain is impacted as well but careful examination can show the spinal cord is also affected $[10,14,19]$. Spinal cord ischaemia is a serious neurological condition and causes neuronal death, functional neurological loss and paraplegia in up to $33 \%$ of patients affected [19]. Thus prompt diagnosis and treatment may significantly alter outcomes. Often there is no relevant past medical history, or signs of inflammation [14], although vascular risk factors are usually present, less than $50 \%$ of spinal strokes have a definite cause [24].

The mid-thoracic cord around T4-T8 is known as the ischaemic "watershed region" and because of fewer radicular arteries and narrowing of the anterior spinal artery in this area, was thought to be particularly sensitive to hypoperfusion [11,22]. However in terms of spinal stroke, this traditional view has recently come under scrutiny $[12,25]$ and as seen in postmortem studies conducted by Duggal et al. 66 patients which had ischaemic myelopathy (secondary to cardiac arrest or severe systemic hypotension) showed $95.5 \%$ had involvement of the lumbosacral cord, whilst the thoracic cord was only affected in $7.6 \%$ of cases [26)]. Hence the lumbosacral cord which, is mainly supplied by the singular artery of Adamkiewicz, is the most sensitive to hypoperfusion; possibly due to its greater metabolic demands (lumbosacral enlargement) [22,26]. A saddle embolus can cause occlusion of the GRA causing distal cord ischaemia [27]. The cauda equina is mainly supplied by lateral and medial sacral arteries, which arise from the internal iliac artery [27].

Spinal cord infarction presents with sudden onset of severe pain, radiating down the legs (radicular) [24] and progressive sensori-motor deficits in the initial stages. In lumbosacral involvement there may be a rapidly progressive bilateral flaccid paresis initially, with loss of tendon reflexes, possibly an absent plantar response and urinary retention [10,11,14,22,24]. Bowel dysfunction can also develop [19]. The pain may be throbbing or burning in nature and disappear after 2 to 3 days [24]. A sensory level below the infarction is usually present however passive movement may be retained if the posterior circulation is preserved [10,11], with gross rather than fine sensation more affected [14]. As it happens the anterior circulation is more often affected [14], with $88 \%$ of infarcts in the central territory of the anterior spinal artery [24]. If the infarction is established it is irreversible and spastic paraplegia, spastic bladder and hyper-reflexia may develop [10,11]. Cervical infarction can cause bilateral paresis in the upper limb [14]. Saddle anaesthesia may also be present [24]. 
Investigations involve excluding other causes, and later confirmation of the ischaemia with T2 weighted MRI imaging [11,14]. In the initial stages diffusion weighted MRI can detect spinal cord oedema, which is a precursor to infarction [14]. CSF protein can also be raised in some cases $[9,11,24]$. Treatment is usually symptomatic with a variable outcome ${ }^{[11]}$.

\section{Abdominal aortic aneurysms, spinal stroke and CES}

As we can see, the symptoms and even aetiology of spinal stroke and CES may well overlap. Although history and examination can indicate other causes of CES, spinal stroke is moreover a diagnosis of exclusion, confirmed only by MRI[*] (fig 5,6) of the cord [11]. In the literature, there are not many cases to report relationship between the abdominal aortic aneurysm, spinal stroke and cauda equina syndrome.

P. Jauslin et al[32] in 1991 describe a case report of cauda equina syndrome associated with an Aorto-caval Fistula. In this particular case history and clinical examination demonstrated symptoms of: pain, tachycardia, peri-umbilical tenderness and a systolo-diastolic murmur. The patient was apyrexial and normotensive with femoral pulses present but cyanosis in both legs. Neurologically, there was perineal anaesthesia ("anesthesie en selle") with markedly reduced anal sphincter tone, paresis and anaesthesia of the left leg in the L1 territory. Lumbar percussion was painless and deep sensitivity was intact.

Verneuil A et Al[33] in 1997 reported a case of persistent cauda equina syndrome following bilateral aortoiliac dissection as a complication of cardiac angiography. In this case report they describe the symptoms as follows: numbness in the gluteal region and the soles of the feet with urinary retention and faecal incontinence. In this case report, the MRI scan of the lumbar region was completely normal in the absence of anal tone in rectal manometry. Electromographic study (EMG) was consistent with cauda equine at level S1 \& S2.

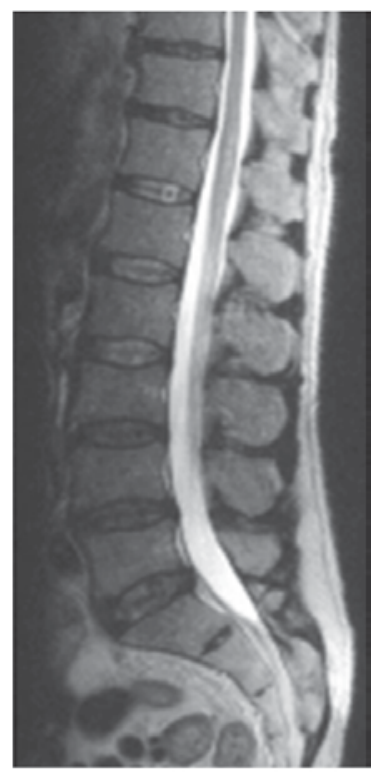

Fig. 5. Normal MRI scan 


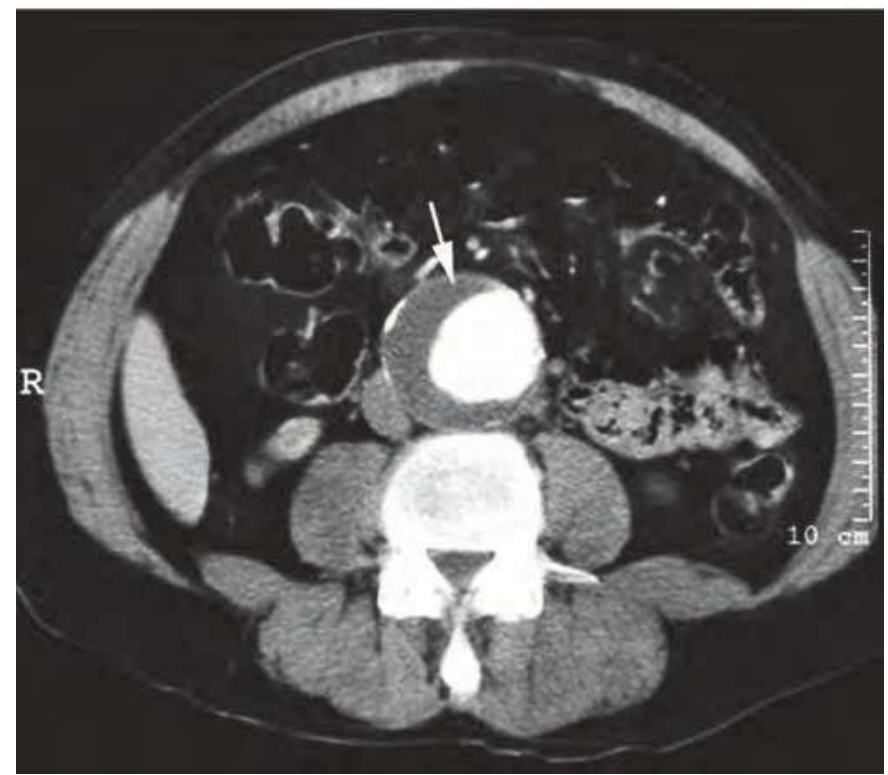

[**] Copyright for the Author of this Chapter who is the same the Author of the Case Report

Fig. 6. Abdominal Aortic Aneurysm

Patel NM et Al[34] published in 2002 a case report describing aortic dissection presenting as an acute cauda equina syndrome. In this case, the patient had acute, but transient, neck pain following a short coughing episode. The patient was able to walk to the restroom, but began to have severe low-back pain and lower extremity numbness and weakness that rapidly progressed to frank lower extremity paralysis. While en-route to the hospital, the patient became incontinent of both bowel and bladder. Upon admission to the emergency department, the patient complained of low-back pain, bilateral hip and thigh pain, and the inability to move or feel the lower extremities. The diagnosis of dissecting aortic aneurysm was made on the basis of a CT scan.

An unusual cause of spinal cord infarction, first documented in 2009 by EL-Osta et al. is from emboli thrown off an abdominal aortic aneurysm (AAA), with symptoms mimicking CES [28].

An aneurysm is a focal increase in diameter of the aorta of at least $50 \%$ in relation to the normal expected diameter [29]. Though by definition it can occur anywhere in the abdominal cavity the vast majority are infra-renal [30]. Thrombus frequently collects in the walls of an aneurysm and fragments can easily be thrown-off in the direction of a spinal artery, thus causing spinal cord ischaemia.

In this particular case the patient had sudden onset of lower back whilst heavy lifting. The pain radiated to his groins and there was a progressive bilateral weakness worse on one side. On examination profound neurological deficit was seen in both legs, with arreflexia, altered sensation and reduced bladder sensation and anal tone.

Although MRI showed lumbar disc protrusions there was no cord compression, hence spinal arteriography was performed. The final diagnosis was through a combination of 
clinical, diagnostic and radiological tests. CT had shown a 6.6 by $5.8 \mathrm{~cm}$ infra-renal aneurysm[28].

As a result of reviewing the literature, it seems that patients who are admitted with query cauda equina syndrome and with unusual symptoms, should be investigated for other causes. It seems that the patient had more than simply weakness in the leg, paraesthesia and decreased anal tones. Some patients will present with abdominal discomfort and neck discomfort. Past medical history may be unremarkable with no trauma, but sudden onset cauda equina symptoms. In those particular cases, the responsible surgeon has to be extra cautious especially in orthopaedics.

In all four cases that have been reported in the literature, none of the patients recovered fully and in one case the patient deteriorated and died immediately. However, one patient did recover partially and the authors could not explain this. This implies that either way patients will have some gross disability and this may be as a result of delayed treatment.

\section{Conclusion}

Though spinal stroke is uncommon the high level of incidence and prevalence of AAAs may mean such cases may become more common, and hence should be an important thought in the surgeons mind when assessing CES. The key difference between atherosclerosis and thrombi in the spinal arteries will be the speed of onset of symptoms. With sudden CES-like symptoms affecting the patient with a significant spinal artery thrombus.

Initially after thorough history and examination (including abdominal examination for a pulsatile mass [31]) all other causes of CES must be ruled out, hence urgent CT/MRI of the spinal cord is appropriate.

On the other hand, when acute aortic dissection is suspected, an emergent diagnostic workup should be initiated with ultrasound techniques involving either a transthoracic or transesophageal approach or computerized tomography. Magnetic resonance imaging is also a diagnostic resource but may be difficult to obtain rapidly. Other vascular phenomena, such as aneurysms of the abdominal aorta or pelvic arteries, can also cause neurological symptoms, further pointing to the need for close attention to the vascular tree during orthopaedic examination[35].

Prompt diagnosis of such disorders may help in hastening treatment, which is particularly important in the context of neurological ischaemia, which can be irreversible. Thus this may help to improve outcomes for such patients in the future.

Figures

1. Gray H (1918). Lateral view of the vertebral column in: Anatomy of the Human Body. 20, U.S. edition. Philadelphia: Lea \& Febiger. From www.wikipedia.com.

2. Gray H (1918). Median sagittal section of two lumbar vertebræ and their ligaments. Anatomy of the Human Body. 20th U.S. edition. Philadelphia: Lea \& Febiger. From www.wikipedia.com.

3. Debivort user (2007). Annotated diagram of cervical vertebrae. From www.wikipedia.com.

4. Gray H (1918). Cauda equine in:Anatomy of the Human Body. 20th U.S. edition. Philadelphia: Lea \& Febiger. From www.wikipedia.com. 
5. El-Osta B, Ghoz A, Singh VK, Saed E, Abdunabi M (2009). Spontaneous spinal cord infarction secondary to embolism from an aortic aneurysm mimicking as cauda equina due to disc prolapse: a case report. Cases J 2: 7460.

\section{References}

[1] Jensen MC, Brant-Zawadzki MN, Obuchowski N, Modic MT, Malkasian D, Ross JS (1994). Magnetic resonance imaging of the lumbar spine in people without back pain. N Engl J Med 14;331(2): 69-73.

[2] Deyo RA, Rainville J, Kent DL (1992). What can the history and physical examination tell us about low back pain? JAMA 12;268(6): 760-5.

[3] Referral Advice. A guide to appropriate referral from general to specialist services (2001). National Institute for Clinical Excellence.

[4] Moore KL \& Dalley AF (1999). Clinically orientated anatomy. $4^{\text {th }}$ edition. Lippincott Williams \& Wilkins.

[5] Abrahams PH, Marks Jr SC, Hutchings RT (2003). McMinn's colour atlas of human anatomy. $5^{\text {th }}$ edition. Mosby.

[6] Crossman AR \& Neary D (2005). Neuroanatomy. An illustrated colour text. $3^{\text {rd }}$ edition. Elselvier Churchill Livingstone.

[7] Holdsworth F (1970). Review article fractures, dislocations, and fracture-dislocations of the spine. J Bone Joint Surg Am 52: 1534-1551.

[8] Maynard FM Jr, Bracken MB, Creasey G, Ditunno JF Jr, Donovan WH, Ducker TB, Garber SL, Marino RJ, Stover SL, Tator CH, Waters RL, Wilberger JE, Young W (1997). International Standards for Neurological and Functional Classification of Spinal Cord Injury. American Spinal Injury Association. Spinal Cord 35(5): 266-74.

[9] Silver JR \& Buxton PH (1974). Spinal stroke. Brain 97: 539-550.

[10] Editorial: spinal stroke (1974). The Lancet 30;2(7892): 1299-1300.

[11] Lindsay KW, Bone I (2004). Neurology and neurosurgery illustrated. Fourth edition. Churchill Livingstone.

[12] Cheshire WP, Santos CC, Massey EW, Howard JF Jr (1996). Spinal cord infarction: Etiology and outcome. Neurology 47:321-330.

[13] Olmarker K, Rydevik B, Holm S (1989). Edema formation in spinal nerve roots induced by experimental, graded compression. An experimental study on the pig cauda equina with special reference to differences in effects between rapid and slow onset of compression. Spine 14(6): 569-73.

[14] Küker W, Weller M, Klose U, Krapf H, Dichgans J, Nägele T (2004). Diffusionweighted MRI of spinal cord infarction--High resolution imaging and time course of diffusion abnormality. J Neurol 251: 818-824

[15] Gitelman A, Hishmeh S, Morelli BN, Joseph SA Jr, Casden A, Kuflik P, Neuwirth M, Stephen M (2008). Cauda Equina Syndrome: A Comprehensive Review. Am J Orthop 37(11): 556-562.

[16] Bonnin JG (1945). Sacral fractures and injuries to the cauda equina. J Bone Joint Surg Am 27: $113-127$. 
[17] Auroy Y, Narchi P, Messiah A, Litt L, Rouvier B, Samii K (1997). Serious complications related to regional anesthesia: results of a prospective survey in France. Anesthesiology 87(3): 479-86.

[18] NINDS Spinal Cord Infarction Information Page. National Institute of Neurological Disorders and Stroke.

http://www.ninds.nih.gov/disorders/spinal_infarction/spinal_infarction.htm\#W hat_is

[19] Thurnher MM \& Bammer R (2006). Diffusion-weighted MR imaging (DWI) in spinal cord ischemia. Neuroradiology 48: 795-801.

[20] Silver JR \& Buxton PH (1974). Spinal stroke. Brain 97: 539-550.

[21] Börnke C, Schmid G, Szymanski S Schöls L (2002). Vertebral body infarction indicating midthoracic spinal stroke. Spinal Cord 40: 244-247.

[22] Rossi D, Goodwin D, Cruzzavala J (2008). Spinal cord infarction following coronary artery bypass grafting surgery. WV Med J 104(6): 24-25.

[23] Novy J, Carruzzo A, Maeder P, Bogousslavsky J (2006). Spinal cord ischemia. Clinical and Imaging Patterns, Pathogenesis, and Outcomes in 27 Patients. Arch Neurol 63:1113-1120.

[24] Masson C, Pruvo JP, Meder JF, Cordonnier C, Touzé E, de la Sayette V, Giroud M, Mas JL, Leys D (2004). Spinal cord infarction: clinical and magnetic resonance imaging findings and short term outcome. J Neurol Neurosurg Psychiatry 75: 14311435.

[25] Jellinger KA (1997) Spinal cord water- shed. Neurology 48:1474.

[26] Duggal N \& Lach B (2002). Selective vulnerability of the lumbosacral spinal cord after cardiac arrest and hypotension. Stroke 33: 116-121.

[27] Chandrashekar G, Acharya PT, Rao J, Kumar RS, Nayak G (1994). Recovery from paraplegia following aortic saddle embolism. Case report. Paraplegia 32: 112116.

[28] El-Osta B, Ghoz A, Singh VK, Saed E, Abdunabi M (2009). Spontaneous spinal cord infarction secondary to embolism from an aortic aneurysm mimicking as cauda equina due to disc prolapse: a case report. Cases J 2: 7460.

[29] Ernst CB (1993). Abdominal Aortic Aneurysm. N Engl J Med 328:1167-1172.

[30] Lederle FA, Johnson GR, Wilson SE, Chute EP, Littooy FN, Bandyk D, Krupski WC, Barone GW, Acher CW, Ballard DJ (1997). Prevalence and Associations of Abdominal Aortic Aneurysm Detected through Screening. Ann Intern Med 126: 441449.

[31] Estes JE Jr (1950). Abdominal Aortic Aneurysm: A Study of One Hundred and Two Cases. Circulation 2: 258-264.

[32] Pierre A. Jauslin, Alex F. Müller, Peter Myers, Vladimir Velebit. Cauda equina syndrome associated with an Aorto-caval fistula. Eur J Vasc Surg. 1991 Aug;5(4):471-3.

[33] Verneuil A, Boeve BF, Fulgham JR, Johnson CM, Wright RS.Persistent cauda equina syndrome following bilateral aortoiliac dissection as a complication of cardiac angiography. Cathet Cardiovasc Diagn. 1997 Apr;40(4):377-9. 
[34] Patel NM, Noel CR, Weiner BK. Aortic dissection presenting as an acute cauda equina syndrome : a case report. J Bone Joint Surg Am. 2002 Aug;84-A(8):1430-2

[35] Mignucci LA, Bell GR. Differential diagnosis of sciatica. The spine.4th ed; 1999. p 89107. 


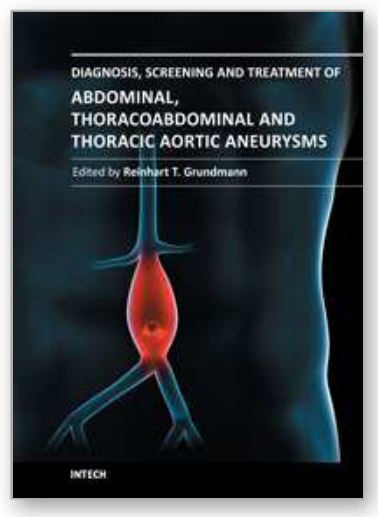

\author{
Diagnosis, Screening and Treatment of Abdominal, \\ Thoracoabdominal and Thoracic Aortic Aneurysms \\ Edited by Prof. Reinhart Grundmann
}

ISBN 978-953-307-466-5

Hard cover, 414 pages

Publisher InTech

Published online 12, September, 2011

Published in print edition September, 2011

This book considers mainly diagnosis, screening, surveillance and treatment of abdominal, thoracoabdominal and thoracic aortic aneurysms. It addresses vascular and cardiothoracic surgeons and interventional radiologists, but also anyone engaged in vascular medicine. The high mortality of ruptured aneurysms certainly favors the recommendation of prophylactic repair of asymptomatic aortic aneurysms (AA) and therewith a generous screening. However, the comorbidities of these patients and their age have to be kept in mind if the efficacy and cost effectiveness of screening and prophylactic surgery should not be overestimated. The treatment recommendations which will be outlined here, have to regard on the one hand the natural course of the disease, the risk of rupture, and the life expectancy of the patient, and on the other hand the morbidity and mortality of the prophylactic surgical intervention. The book describes perioperative mortality after endovascular and open repair of AA, long-term outcome after repair, and the cost-effectiveness of treatment.

\title{
How to reference
}

In order to correctly reference this scholarly work, feel free to copy and paste the following:

Masood Rehman Moghul and Bassel El-Osta (2011). Relationships Between AAA and Cauda Equina Syndrome, Diagnosis, Screening and Treatment of Abdominal, Thoracoabdominal and Thoracic Aortic Aneurysms, Prof. Reinhart Grundmann (Ed.), ISBN: 978-953-307-466-5, InTech, Available from: http://www.intechopen.com/books/diagnosis-screening-and-treatment-of-abdominal-thoracoabdominal-andthoracic-aortic-aneurysms/relationships-between-aaa-and-cauda-equina-syndrome

\section{INTECH}

open science | open minds

\section{InTech Europe}

University Campus STeP Ri

Slavka Krautzeka 83/A

51000 Rijeka, Croatia

Phone: +385 (51) 770447

Fax: +385 (51) 686166

www.intechopen.com

\section{InTech China}

Unit 405, Office Block, Hotel Equatorial Shanghai

No.65, Yan An Road (West), Shanghai, 200040, China 中国上海市延安西路65号上海国际贵都大饭店办公楼405单元

Phone: +86-21-62489820

Fax: $+86-21-62489821$ 
(C) 2011 The Author(s). Licensee IntechOpen. This chapter is distributed under the terms of the Creative Commons Attribution-NonCommercialShareAlike-3.0 License, which permits use, distribution and reproduction for non-commercial purposes, provided the original is properly cited and derivative works building on this content are distributed under the same license. 